Jurnal Dinamika Sosial Ekonomi Vol.20 No.2, Desember 2019 : 109-117

ISSN 1411-593X (print)

\title{
PERAN STAKEHOLDERS DALAM PENGELOLAAN HUTAN RAKYAT (STUDI KASUS PADA KTH GUNUNG BUJEL ASRI DESA SIDOHARJO KECAMATAN SAMIGALUH KABUPATEN KULON PROGO)
}

\author{
The Role Of Stakeholders in Community Forest Management \\ (Case Study in KTH Gunung Bujel Asri Sidoharjo Village Samigaluh \\ District Kulonprogo Regency)
}

\author{
Gryana Rakhmatullah*, Daru Retnowati, Teguh Kismantoroadji \\ Program Studi Agribisnis Fakultas Pertanian \\ Universitas Pembangunan Nasional "Veteran" Yogyakarta \\ Jl. SWK 104, Condongcatur, Kecamatan Depok, Kabupaten Sleman, Yogyakarta \\ email korespondensi : gryana.174@gmail.com
}

Diterima tanggal : 16 Juli 2019 ; Disetujui tanggal : 12 Oktober 2019

\begin{abstract}
The research was aimed to (1) evaluate the management of Madigondo community forest by Gunung Bujel Asri farmers groups in Sidoharjo Village, Samigaluh sub-district, Kulonprogo district (2) Evaluate the stakeholders' role in the management of Madigondo community forest in Sidoharjo Village, Samigaluh sub-district, Kulonprogo district. (3) Evaluate the results of activities after three forest management in Sidoharjo village, Samigaluh sub-district, Kulonprogo district. This research was a qualitative research with the case study as its implementation method. The technique for taking the informants has done by purposive sampling. Data collection techniques that being used were interviews, observation and documentation, while for data analysis techniques used descriptive qualitative and validity of the data obtained has beentested with data collection triangulation techniques. The results of this research gave some conclusions that (1) Management of Madigondo community forest by KTH Gunung Bujel Asri has done through governance institutions management, regional management, and business management. (2) Stakeholders that involved in the management of Madigondo community forests such as the Forestry and Plantation Official D.I.Yogyakarta, BPDASHL Serayu Opak Progo, and PUPR D.I.Yogyakarta (3) Three forest management provide the positive impact in terms of the ecology of the community forest, economy and social culture of the community.
\end{abstract}

Keywords: Community Forest Management, KTH, Stakeholder

\begin{abstract}
ABSTRAK
Penelitian ini bertujuan (1) Mengkaji pengelolaan hutan rakyat Madigondo oleh Kelompok tani hutan rakyat Gunung Bujel Asri di Desa Sidoharjo Kecamatan Samigaluh Kabupaten Kulonprogro (2) Mengkaji peran stakeholders dalam
\end{abstract}


pengelolaan hutan rakyat Madigondo di Desa Sidoharjo Kecamatan Samigaluh Kabupaten Kulonprogo (3) Mengkaji hasil kegiatan setelah adanya tiga kelola hutan di Desa Sidoharjo Kecamatan Samigaluh Kabupaten Kulonprogo. Penelitian ini merupakan penelitian kualitatif dengan metode pelaksanaan yaitu studi kasus. Teknik pengambilan informan dilakukan dengan purposive sampling. Teknik pengumpulan data yang digunakan adalah wawancara, observasi, dan dokumentasi, sedangkan untuk teknik analisis data menggunakan deskriptif kualitatif dan keabsahan data yang diperoleh akan diuji dengan teknik triangulasi pengumpulan data. Hasil penelitian ini memberikan kesimpulan bahwa (1) Pengelolaan hutan rakyat Madigondo oleh KTH Gunung Bujel Asri dilakukan melalui kelola kelembagaan, kelola kawasan, dan kelola usaha (2) Stakeholders yang berperan dalam pengelolaan hutan rakyat Madigondo yaitu Dinas Kehutanan dan Perkebunan D.I.Yogyakarta, BPDASHL Serayu Opak Progo, dan PUPR D.I.Yogyakarta (3) Tiga kelola hutan memberikan dampak yang postif pada segi ekologi hutan rakyat, ekonomi, dan sosial budaya masyarakat.

Kata Kunci : Pengelolaan Hutan Rakyat, KTH, Stakeholders

\section{PENDAHULUAN}

Desa Sidoarjo merupakan salah satu desa yang berada di kecamatan Samigaluh Kabupaten Kulonprogo D.I. Yogyakarta. Letak desa yang berada dikawasan perbukitan ini menjadi desa Sidoharjo mempunyai potensi yang sangat besar baik dari segi wisata, perkebunan, dan sumber daya alamnya. Desa Sidoharjo memiliki berbagai macam potensi yang dapat dikembangkan, salah satu potensi yang ada yaitu perkebunan hutan rakyat yang ditanami berbagai macam tanaman keras.

Pada tahun 2014 dibentuklah kelompok tani hutan yaitu kelompok tani hutan Gunung Bujel Asri. Kelompok ini melakukan beberapa macam kelola hutan, yaitu berupa kelola kelembagaan, kelola kawasan dan kelola usaha. Didalam berbagai kelola tersebut ada berbagai kegiatan yang dilakukan oleh KTH Gunung Bujel Asri antara lain pengelolaan administrasi kelompok, pengelolaan hutan rakyat, pemanfaatan lahan bawah tegakan hutan, pelestarian sumber air, pemanfaatan jasa lingkungan, pelestarian satwa liar, serta aneka usaha kehutanan dari kayu. Pada setiap 35 hari atau minggu kliwon dilaksanakan pertemuan rutin antar anggota kelompok untuk membahas kegiatan, kemajuan dan pengembangan kelompok tani hutan kedepan. Dengan adanya monitoring dan evaluasi terjadi beberapa kendala oleh kelompok. 
Rakhmatullah et.al./Jurnal Dinamika Sosial Ekonomi Vol.20 No.2, Desember 2019

Para pemangku kepentingan itu lebih sering disebut dengan stakeholder. Para pihak terkait atau yang lazim dikenal dengan istilah stakeholder oleh (Freeman, 1984 dalam Wakka, 2013) didefenisikan sebagai pihak-pihak yang dapat mempengaruhi atau dipengaruhi (menerima dampak) dari keputusan yang diambil. Menurut Nugroho dalam Mahfud et.al. (2014), stakeholder dalam program pembangunan diklasifikasikan berdasarkan peranannya, antara lain: policy creator, koordinator, fasilitator, implementer, akselerator. Terdapat dua kunci dalam analisis pemangku kepentingan, yaitu kepentingan (interest) dan pengaruh (power). Berdasarkan pengaruh (power) dan kepentingan (interest) yang dimiliki oleh setiap stakeholders maka stakeholders dapat dikategorikan menjadi empat jenis yaitu (Reed, 2009 dalam Wakka, 2014):

a. Stakeholders dengan tingkat kepentingan (interest) yang tinggi tetapi memiliki pengaruh (power) yang rendah diklasifikasikan sebagai Subyek (Subjects).

b. Stakeholders dengan tingkat kepentingan (interest) dan pengaruh (power) yang tinggi diklasifikasikan sebagai Pemain Kunci (Key Players).

c. Stakeholders dengan tingkat kepentingan (interest) dan pengaruh (power) yang rendah diklasifikasikan sebagai Pengikut Lain (Crowd).

d. Stakeholders dengan tingkat kepentingan (interest) yang rendah tetapi memiliki pengaruh (power) yang tinggi diklasifikasikan sebagai Pendukung (Contest setters).

Penelitian ini bertujuan untuk mengkaji pengelolaan hutan rakyat Madigondo oleh KTH Gunung Bujel Asri, mengkaji peran stakeholders, dan mengkaji setelah adanya tiga kelola hutan di Desa Sidoharjo Kecamatan Samigaluh Kabupaten Kulonprogo.

\section{METODE PENELITIAN}

Penelitian ini dilakukan di KTH Gunung Bujel Asri yang berlokasi di Desa Sidoharjo Kecamatan Samigaluh Kabupaten Kulon Progo. Waktu Penelitian dilakukan bulan Maret sampai dengan Juni 2019. Jenis penelitian yang digunakan adalah penelitian kualitatif dengan pendekatan studi kasus. Fokus penelitian yang diamati ialah KTH Gunung Bujel Asri, subyek penelitian ini adalah Staf Sie. 
Evaluasi BPDASHL Serayu Opak Progo, Kasie PKP PUPR D.I.Yogyakarta, PPL dari Dinas Kehutanan dan Perkebunan D.I. Yogykarta, Sekertaris KTH Gunung Bujel Asri Informan kunci dalam penelitian ini adala ketua KTH Gunung Bujel Asri. Teknik penentuan informan dilakukan dengan cara purposive sampling yaitu teknik pengambilan sampel sumber data dengan pertimbangan tertentu, misalnya orang tersebut dianggap paling tahu tentang apa yang kita harapkan (Sugiyono, 2011).

Teknik pengumpulan data yang digunakan dalam penelitian kualitatif adalah observasi, wawancara, dan dokumentasi. Dalam penelitian ini untuk Dalam penelitian ini untuk menguji keabsahan data menggunakan teknik triangulasi, yang dilakukan dengan cara memanfaatkan hal-hal (data) lain untuk pengecekan atau perbandingan data (Moleong, 2014). Miles dan Huberman (1984) dalam Sugiyono (2016) mengemukakan bahwa akivitas dalam analisis data kualitatif dilakukan secara interaktif dan berlangsung secara terus menerus sampai tuntas, sehingga datanya sudah jenuh. Aktivitas dalam analisis data yaitu data reduction, data display, dan conclusion drawing/verification.

\section{HASIL DAN PEMBAHASAN}

Pengelolaan Hutan Rakyat Madigondo Oleh Kelompok Tani Hutan Rakyat Gunung Bujel Asri di Desa Sidoharjo Kecamatan Samigaluh Kabupaten Kulonprogro

1. Perencanaan (Planning)

Tujuan dari KTH Gunung Bujel Asri yaitu kelompok mampu secara mandiri, berdaya saing dan berperan aktif dalam mengelola hutan rakyat melalui meningkatkan usaha kehutanan yang tetap menjaga kelestarian hutan atau tidak mengeksploitasi hutan secara berlebih sehingga berdampak terhadap rusaknya alam sekitar. Dari tujuan yang ditetapkan oleh KTH Gunung Bujel Asri dapat dilihat bahwa KTH Gunung Bujel Asri harapannya bisa menjadi kelompok yang mandiri dalam mengelola kelompoknya sendiri, mempunyai daya saing yang tinggi serta berperan aktif dalam melestarikan hutan rakyat. KTH Gunung Bujel Asri beranggapan bahwa tujuan sudah mengacu pada juknis Peraturan Kementrian 
Rakhmatullah et.al./Jurnal Dinamika Sosial Ekonomi Vol.20 No.2, Desember 2019

Lingkungan Hidup dan Kehutanan nomor P.89/MENLHK/SETJEN /KUM.1/8/2018 tentang Pedoman Kelompok Tani Hutan, sehingga tidak perlu visi dan misi yang ditetapkan. Akibat dari tidak adanya visi dan misi yang ditetapkan oleh KTH Gunung Bujel Asri, kelompok tidak memiliki tahapantahapan yang jelas untuk menggapai cita-cita yang diinginkan. Kegiatan perencanaan KTH Gunung Bujel Asri dilakukan adanya keterlibatan dari pihak lain secara langsung. Tujuan dari KTH Gunung Bujel Asri ini disepakati bersamasama oleh anggota kelompok yang waktu awal pembentukan masih berjumlah 6 orang salah satunya yaitu Bapak Mashuri yang menjadi Ketua KTH Gunung Bujel Asri dan didampingi oleh pihak PPL dari Dinas Kehutan dan Perkebunan D.I.Yogyakarta.

\section{Pengkoorganisasian (Organizing)}

Struktur organisasi KTH Gunung Bujel Asri dibuat pada tahun 2014 yang bersifat sederhana berupa ketua, sekertaris, bendahara dan anggota, belum ada bagian-bagian yang lebih spesifik lainnya kemudian lebih diperinci dan ditambah bagian-bagianya sesuai kebutuhan kelompok pada tahun 2017, ditahun yang sama ketika KTH Gunung Bujel Asri akan naik tingkatan kelas dari yang awalnya tingkat pemula menjadi tingkat madya. Alasan dibuatnya struktur organisasi tersebut dibuat suapaya dalam kegiatan kelompok ada yang bertanggung jawab terhadap setiap tugas-tugas yang dilaksanakan dan bagian yang mengkoordinir. Dalam tugas pokok dan fungsi yang ada pada struktur organisasi KTH Gunung Bujel Asri Tidak semua anggota memahami tupoksi yang ada pada kelompok sehingga beberapa anggota kurang optimal dalam menjalankan tupoksinya

\section{Pelaksanaan (Actuating)}

Kegiatan actuating (pelaksanaan) KTH Gunung Bujel Asri dilakukan melalui 3 kelola yaitu kelola kelembagaan, kelola kawasan dan kelola usaha.

4. Pengawasan (Controlling)

Kegiatan controlling (pengawasan) pada KTH Gunung Bujel Asri dilakukan melalui pertemuan-pertemuan rutin yang dilaksanakan setiap 35 hari sekalin atau pada setiap Minggu Kliwon serta melalui pertemuan insedental saat dibutuhkan. Dalam pertemuan-pertemuan tersebut biasanya membahas kegiatan- 
kegiatan yang akan dilaksanakan maupun sudah dilaksanakan terkait juga dengan kendala dalam pelaksanakan kegiatan.

\section{Peran Stakeholders Dalam Pengelolaan Hutan Rakyat Madigondo di Desa Sidoharjo Kecamatan Samigaluh Kabupaten Kulonprogo}

Jalinan kerja sama antar-stakeholder berdampak pada pemahaman masyarakat akan manfaat dan pentingnya kegiatan yang dijalanan (Alviya et.al., 2016). Pengelolaan Hutan Rakyat Madigondo oleh KTH Gunung Bujel Asri terdapat beberapa pihak pemangku kepentingan atau stakeholders yaitu Sie Penyuluhan Dinas Kehutanan dan Perkebunan D.I.Yogyakarta, Sie Evaluasi BPDASHL Serayu Opak Progo, dan Sie PPK PUPR D.I.Yogyakarta. Dari setiap masing-masing pemangku kepentingan atau stakeholders peran masing-masing.

Sie Penyuluhan Dinas Kehutan dan Perkebunan D.I.Yogyakarta termasuk Stakeholder Pendukung (Contest Setter) yang memiliki pengaruh (power) yang tinggi karena memberikan pelatihan berupa Pelatihan Partisipatif Kenaikan Kelembagaan dan pendampingan dari mulai terbentuknya KTH Gunung Bujel Asri sampai sekarang, sehingga KTH Gunung Bujel Asri yang awalnya kelas pemula menjadi kelas madya dan pada tahun 2018, KTH Gunung Bujel Asri meraih penghargaan sebagai juara harapan ke-3 dalam Lomba Wana Lestari yang diselenggarakan oleh Kementerian Lingkungan Hidup dan Kehutanan setiap tahun.

Sie Penyuluhan Dinas Kehutan dan Perkebunan D.I.Yogyakarta juga memberikan bibit tanaman kepada KTH Gunung Bujel Asri serta mempunyai kewenangan untuk mengkoordinasi kegiatan pada instansi lain untuk pemberian bantuan Kebun Bibit Rakyat dari BPDASHKL Serayu Opak Progo, serta memiliki kepentingan (interest) rendah karena meskipun memenuhi misi yang diemban untuk mewujudkan hutan lestari dimana pemanfaatan secara optimal dilakukan dengan memperhatikan jaminan keberlangsungan fungsi hutan secara berkelanjutan baik secara ekologi, ekonomi dan sosial budaya sehingga mampu mendukung peningkatan kesejahteraan masyarakat, tetapi peran yang diberikan maupun bantuan dari pemangku kepentingan atau stakeholder ini atas dasar 
Rakhmatullah et.al./Jurnal Dinamika Sosial Ekonomi Vol.20 No.2, Desember 2019

kebutuhan atau keinginan dari kelompok.

Stakeholder Pendukung (Contest Setter) yaitu Sie Evaluasi BPDASHL Serayu Opak Progo dan Sie PPK PUPR D.I.Yogyakarta, kedua pemangku kepentingan atau stakeholders tersebut tidak memiliki kepentingan yang tinggi namun memiliki pengaruh yang diberikan melalui perannya dalam pengelolaan hutan rakyat Madigondo oleh KTH Gunung Bujel Asri, sehingga perlu menjalin hubungan yang baik suapaya bisa mendukung pencapaian tujuan dari KTH Gunung Bujel Asri dalam mengelola hutan rakyat Madigondo.

\section{Hasil kegiatan Setelah Adanya Tiga Kelola Hutan di Desa Sidoharjo Kecamatan Samigaluh Kabupaten Kulonprogo.}

Adanya berbagai macam kelola hutan yang dilakukan yaitu Kelola Kelembagaan, Kelola Kawasan, dan Kelola UsahaMadigondo oleh KTH Gunung Bujel Asri memberikan dampak yang postif pada segi ekologi hutan rakyat karena hutan dan sumber air menjadi seamakin lestari, segi ekonomi menjadi lebih baik karena masyarakat yang tadinya hanya mendapatkan keuntungan dari hasil hutan bertambah dengan adanya wisata watu tekek ada yang berdagang dan ikut serta menjadi pengelola tempat wisata, dan segi sosial budaya masyarakat menjadi lebih baik karena sering melalukan kegiata-kegiatan yang ada dihutan dilakukan dengan bersama-sama.

Pengelolaan hutan rakyat dengan perbaikan/penambahan kerapatan tanaman utama maupun pendukungnya mampu menekan erosi dan limpasan permukaan sampai di bawah nilai erosi dan limpasan permukaan yang diperbolehkan/ideal serta mampu mempertahankan produktivitas, pendapatan petani, cadangan karbon serta penyerapatan tenaga kerja dengan nilai minimal sama dengan kondisi eksisting serta mampu mempertahankan produktivitas, pendapatan petani, cadangan karbon serta penyerapatan tenaga kerja dengan nilai minimal sama dengan kondisi eksisting (Sudiana, et.al., 2009). 


\section{KESIMPULAN DAN SARAN}

\section{Kesimpulan}

Pengelolaan hutan rakyat Madigondo oleh KTH Gunung Bujel Asri dilakukan Planning dengan menetapkan tujuan yang mengacu pada juknis Peraturan Kementrian Lingkungan Hidup dan Kehutanan, Organizing dilakukan dengan pembuatan struktur organisasi dan tupoksinya, Actuating dilakukan dengan melalui tiga kelola yaitu kelola kelembagaan, kelola kawasan, dan kelola usaha, Controlling dilakukan oleh PPL dan anggota KTH Gunung Bujel Asri dalam pertemuan setiap 35 hari atau Minggu Kliwon serta pertemuan insedental. Pemangku kepentingan atau stakeholders yang berperan dalam pengelolaan hutan rakyat Madigondo yaitu Sie Penyuluhan Dinas Kehutanan dan Perkebunan D.I.Yogyakarta menjadi stakeholder Pendukung (Contest Setter), BPDASHL Serayu Opak Progo menjadi stakeholder Pendukung (Contest Setter), PUPR D.I.Y menjadi stakeholder Pendukung (Contest Setter). Ketiga kelola hutan memberikan dampak yang baik pada segi ekologi hutan rakyat, ekonomi, dan sosial budaya masyarakat.

\section{Saran}

KTH Gunung Bujel Asri bisa menetapkan tujuan kelompok sebagain visinya dan menetapkan misi yang jelas, supaya apa yang sudah dicita-citakan dapat tercapai dengan tahapan-tahapan yang jelas dan tersistem. Tindak lanjut dari Sie Penyuluhan Dinas Kehutanan dan Perkebunan D.I.Yogyakarta terhadap kegiatan Partisipasi Pelatihan Peningkatan Kelembagaan yang diberikan berupa pelatihan lanjutan. Sebaiknya ada kegiatan pengkapasitasan untuk anggota KTH dalam mengelola kelembagaan melalui kegiatan pelatihan-pelatihan secara rutin. Pemberian daya dari pihak PPL atau fasilitator untuk ketua kelompok agar ketua kelompok menjadi lebih mandiri dan tidak selalu bergantung pada pihak PPL. Menumbuhkan kesadaran kelompok dan pemilik usaha untuk bersama-sama dalam mengembangkan kelola usaha, dikarenakan memiliki potensi untuk dijadikan paket ekowisata. 
Rakhmatullah et.al./Jurnal Dinamika Sosial Ekonomi Vol.20 No.2, Desember 2019

\section{DAFTAR PUSTAKA}

Alviya I., Suryandari E.Y., Maryani R., Muttaqin M.Z. 2016. Meningkatkan Peran Pemangku Kepentingan Dalam Pengelolaan Wilayah Hulu Daerah Aliran Sungai Ciliwung. Jurnal Penelitian Sosial dan Ekonomi Kehutanan, 13 (2) : 121-134.

Mahfud M.A.Z, Haryono B.S, dan Anggraeni N.L.V. 2014. Peran dan Koordinasi Stakeholder dalam Pengembangan Kawasan Minapolitan di Kecamatan Nglegok, Kabupaten Blitar. Jurnal Administrasi Publik (JAP), 3 (12) : 2070-2076.

Moleong, Lexy J. 2014. Metodologi Penelitian Kualitatif. Bandung : PT Remaja Rosdakarya.

Sudiana E, Hanani N, Yanuwiadi B, Sumarno. 2009. Pengelolaan Hutan Rakyat Berkelanjutan Di Kabupaten Ciamis, 17 (3): 543-555.

Sugiyono. 2011. Metode Penelitian Kualitatif, Kuantitatif, dan $R \& D$. Bandung : Alfabeta.

Sugiyono. 2016. Metode Penelitian Kombinasi. Bandung : Alfabeta.

Wakka AK., Awang S.A., Purwanto R.H, dan Poedjirahajoe E. 2013. Analisis Stakeholder Pengelolaan Taman Nasional Bantimurung Bulusaraung, Provinsi Sulawesi Selatan. Jurnal Manusia dan Lingkungan 20 (1) : 11-21.

Wakka, A.K. 2014. Analisis Stakeholder Pengelolaan Kawasan Hutan dengan Tujuan Khusus (KHDTK) Mengkendek Kabupaten Tana Toraja Provinsi Sulawesi Selatan. Jurnal Penelitian Kehutanan Wallacea, 3 (1) : 47 - 55. 